\title{
A Política Nacional de Educação Especial na Perspectiva da Educação Inclusiva: a Problemática do Profissional de Apoio à Inclusão Escolar COMO UM DE SEUS EFEITOS ${ }^{1}$
}

\author{
The National Policy of Special Education in the Inclusive Education \\ Perspective: the PRoblematics of the Support School InCLUsion \\ PROFESSIONAL AS ONE OF ITS EFFECTS
}

\author{
Giovani Ferreira BEZERRA²
}

\begin{abstract}
RESUMO: O profissional de apoio à inclusão escolar é a temática deste artigo. Seu objetivo é retomar e analisar a caracterização desse profissional com base nas orientaçôes governamentais e nos documentos legais emanados logo após a publicação da Política Nacional de Educação Especial na Perspectiva da Educação Inclusiva, a fim de compreender o que se espera desse agente e de sua formaçấo no contexto da Educação Especial inclusiva delineado pela citada política. Para tanto, em relação ao desenvolvimento metodológico, adotou-se abordagem qualitativa, conforme os procedimentos técnicos da pesquisa bibliográfica e documental. Pôde-se constatar que o profissional de apoio à inclusão escolar, cuja designação não é unívoca, tem funçôes específicas de cuidado e de monitoria dos alunos público-alvo da Educaçáo Especial, considerada a legislação e diretrizes oficiais, não sendo de sua competência questóes curriculares e didático-pedagógicas. Do ponto de vista legal e normativo, há um silenciamento quanto à formação exigida para desempenho do cargo, exercido por estudantes universitários ou mesmo por pessoas com nível médio de escolaridade. Tais circunstâncias desqualificam a formação especializada e o papel do professor da Educação Especial na promoção do ensino colaborativo, em nome de alternativas consideradas mais econômicas para as redes públicas de ensino.
\end{abstract}

PALAVRAS-CHAVE: Educação Especial. Educaçáo Inclusiva. Atendimento em classe comum. Apoio à pessoa com deficiência.

\begin{abstract}
The supporting school inclusion professional is the theme of this paper. Its objective is to resume and analyze the characterization of this professional based on governmental guidelines and legal documents issued shortly after the publication of the National Policy of Special Education in the Perspective of Inclusive Education, in order to understand what is expected of this agent and his/her education in the context of inclusive Special Education outlined by the above policy. Therefore, regarding the methodological development, a qualitative approach was adopted, according to the technical procedures of the bibliographic and documentary research. It was found that the supporting school inclusion professional, whose designation is not univocal, has specific roles of care and monitoring of target students of Special Education, considering the legislation and official guidelines, but curricular and didactic-pedagogical issues are not within their competence. From a legal and normative point of view, there is a silence regarding the training required for the performance of the position, performed by university students or even people with High School level. Such circumstances disqualify specialized education and the role of the Special Education teacher in the promotion of collaborative teaching, in the name of alternatives considered more economical for public schools.
\end{abstract}

KEYWORDS: Special Education. Inclusive Education. Common class service. Support for the person with disability.

\section{INTRODUÇÃo}

A Política Nacional de Educaçáo Especial na Perspectiva da Educação Inclusiva ([PNEEPEI], 2008) foi divulgada, no Brasil, em 2008 e, desde então, tem impactado na organizaçáo e no funcionamento dos serviços especializados para estudantes com deficiência, transtornos globais do desenvolvimento e altas habilidades/superdotação, considerados o pú-

\footnotetext{
${ }^{1}$ https://doi.org/10.1590/1980-54702020v26e0184

${ }^{2}$ Doutor em Educação. Docente. Faculdade de Educação da UFGD. Universidade Federal da Grande Dourados (UFGD). Dourados/Mato Grosso do Sul/Brasil. E-mail: gfbezerra@gmail.com. ORCID: http://orcid.org/0000-0002-4710-3897
} 
blico-alvo da Educação Especial (PAEE). Basicamente, a PNEEPEI transformou a Educação Especial em um serviço de Atendimento Educacional Especializado (AEE), ofertado, em tese, ao PAEE de forma extraclasse, em regime de contraturno, no espaço-tempo das Salas de Recursos Multifuncionais (SRM), por professores especializados. No entanto, a mesma política não descartou outras formas de apoio aos estudantes PAEE, as quais poderiam ser incorporadas ao contexto da sala de aula comum e a outros espaços escolares onde se fizessem necessárias. Porquanto, foi preconizado que:

Cabe aos sistemas de ensino, ao organizar a educação especial na perspectiva da educação inclusiva, disponibilizar as funções de instrutor, tradutor/intérprete de Libras e guia-intérprete, bem como de monitor ou cuidador aos alunos com necessidade de apoio nas atividades de higiene, alimentação, locomoção, entre outras, que exijam auxílio constante no cotidiano escolar. (PNEEPEI, 2008, p. 17, ênfase adicionada).

Ora, dentre esses serviços elencados no excerto, quero problematizar como um dos legados mais polêmicos dessa política a aparição e a atuação da figura do monitor ou cuidador de estudantes PAEE com necessidades de apoio nas atividades de higiene, alimentação e locomoção. Isso porque, em torno dessa figura, posteriormente designada por vários nomes, vão se projetando determinados (des)entendimentos, expectativas e funçóes ao longo dos últimos mais de dez anos de vigência da PNEEPEI, sem que haja uma regulamentação para o trabalho desse profissional, a ponto de, em muitas circunstâncias, ser confundido com um professor de apoio e até ser assim referido nos discursos escolares. Na síntese de Lopes (2018), que opta pela nomenclatura Profissional de Apoio à Inclusão Escolar (PAIE), à qual também recorro no decorrer deste texto:

Ainda sem função e atribuições bem definidas, sem perfil profissional específico e condições de trabalho desconhecidas, a figura desses PAIE, relativamente, recente nas políticas de escolarização, tem-se tornado cada vez mais frequente e conflituosa nos contextos escolares. [...] esse personagem pode constituir um apoio importante para viabilizar o processo de inclusão escolar de estudantes que requerem esse tipo de apoio, mas que pode ser também usado como mecanismo de barateamento e simplificaçáo do sistema de apoio. (p. 9).

Assim, o objetivo a que me proponho é retomar, confrontar e analisar a caracterização desse profissional com base nas orientações governamentais e nos documentos legais emanados logo após a PNEEPEI, a fim de compreender o que se espera desse agente e de sua formação no contexto da Educação Especial inclusiva. Ao fazê-lo, espero, também, evidenciar as ambiguidades e as contradiçóes que perpassam sua recente atuação, aqui entendida como um dos efeitos ainda pouco discutidos da PNEEPEI em vigência. É nesse sentido que este artigo, resultante de um estudo inédito, apresenta provocaçóes para subsidiar o avanço do conhecimento em torno do modo como, no plano técnico-normativo e legal, se tem organizado (ou não) e sobre quem desempenha, no Brasil, o apoio escolar aos alunos PAEE em classe comum, "considerando a novidade do tema e a ainda escassa produção científica" (Lopes, 2018, p. 9), de maneira a se compreender a "necessidade de se definir diretrizes que regulamentem a variedade de perfis, atribuições, condiçóes de trabalho e modos de atuação" (Lopes, 2018, p. 9) que têm marcado o fazer desse novo personagem nas rotinas escolares. Principalmente quando já se fala, no campo da Educação Especial, em possíveis reformulaçôes da PNEEPEI, promover esse 
debate é tarefa crucial e urgente, pelo que ora socializo minhas reflexôes sobre a temática, sem deixar de, também, tensioná-la em relação ao ensino colaborativo.

\section{Procedimentos metodológicos}

A realização desta pesquisa deu-se mediante abordagem qualitativa (Braun \& Clarke, 2006), conforme os procedimentos técnicos da pesquisa bibliográfica e documental, delineados em Gil (1991). Desse modo, em novembro de 2019, localizei, por meio de buscas online, dissertaçóes e artigos científicos que versavam sobre o profissional de apoio à inclusão escolar. Tais buscas foram empreendidas de modo exploratório, por meio dos mecanismos de pesquisa possibilitados pelo site Google, de forma que tiveram um caráter preliminar e não se deram por via parametrizada ou bibliométrica. Nesses termos, o foco não era estabelecer uma revisão de literatura, não tendo a pretensão de esgotar o assunto, mas, sim, de encontrar indícios suficientes para abordar a questão pesquisada com base nas ocorrências principais fornecidas pelo conhecido buscador online.

Por meio do descritor profissionais de apoio à inclusão escolar PDF foram listadas, de imediato, entre os dez primeiros resultados-padrão, considerados os mais relevantes pelo buscador, duas dissertaçóes pertinentes à pesquisa (Burchert, 2018; Lopes, 2018). A partir da leitura destas, na íntegra, pude ser direcionado à dissertação de Martins (2011), uma vez que ambas a citavam. Como eram recentes, posteriores à PNEEPEI, específicas sobre a temática e relacionadas ao contexto de redes públicas de ensino, optei por defini-las como ponto de partida para o avanço de minhas reflexóes, complementadas por resultados de pesquisas socializadas em artigos também indicados pelas dissertaçóes supracitadas ou que eram de meu conhecimento, porquanto já tenho abordado o assunto em textos anteriores (Bezerra, 2012; Souza, Bezerra, Bezerra, Costa, \& Nozu, 2012; Vicente \& Bezerra, 2017). Ademais, selecionei e compilei documentos legais de abrangência nacional e publicaçóes oficiosas do Ministério da Educação (MEC), tendo por critério serem publicados exclusivamente a partir de 2008 e que abordassem, em seu conteúdo, quaisquer proposiçóes sobre o tema do profissional de apoio à inclusão escolar. Foram, então, delimitados os seguintes documentos, situados entre os anos de 2008 e 2015, porquanto não houve, posterior a esse período, outros que fossem pertinentes ao estudo.

\begin{tabular}{|l|l|c|}
\hline \multicolumn{1}{|c|}{ Documento } & \multicolumn{1}{|c|}{ Ementa } & $\begin{array}{c}\text { Ano de } \\
\text { publicaçáa }\end{array}$ \\
\hline $\begin{array}{l}\text { Política Nacional de Educação } \\
\text { Especial na Perspectiva da Educação } \\
\text { Inclusiva }\end{array}$ & $\begin{array}{l}\text { Documento-base sobre as diretrizes político-opera- } \\
\text { cionais da PNEEPEI no Brasil. }\end{array}$ & 2008 \\
\hline Resolução $n^{\circ} 4$, de $1^{\text {o de outubro }}$ & $\begin{array}{l}\text { Institui Diretrizes Operacionais para o Atendimen- } \\
\text { to Educacional Especializado na Educação Básica, } \\
\text { modalidade Educação Especial. }\end{array}$ & 2009 \\
\hline Nota Técnica $n^{\circ} 19$ & $\begin{array}{l}\text { Profissionais de apoio para alunos com deficiência e } \\
\text { transtornos globais do desenvolvimento matricula- } \\
\text { dos nas escolas comuns da rede pública de ensino. }\end{array}$ & 2010 \\
\hline Lei no 12.764 , de 27 de dezembro & $\begin{array}{l}\text { Institui a Política Nacional de Proteção dos Direitos } \\
\text { da Pessoa com Transtorno do Espectro Autista. }\end{array}$ & 2012 \\
\hline
\end{tabular}




\begin{tabular}{|l|l|c|}
\hline Nota Técnica no 24 & $\begin{array}{l}\text { Orientação aos Sistemas de Ensino para a imple- } \\
\text { mentação da Lei no } 12.764 / 2012 .\end{array}$ & 2013 \\
\hline Decreto no 8.368, de 2 de dezembro & $\begin{array}{l}\text { Regulamenta a Lei no 12.764, de 27 de dezembro } \\
\text { de 2012, que institui a Política Nacional de Proteção } \\
\text { dos Direitos da Pessoa com Transtorno do Espectro } \\
\text { Autista. }\end{array}$ & 2014 \\
\hline Lei no 13.146, de 6 de julho & $\begin{array}{l}\text { Institui a Lei Brasileira de Inclusão da Pessoa com } \\
\text { Deficiência (Estatuto da Pessoa com Deficiência). }\end{array}$ & 2015 \\
\hline
\end{tabular}

Quadro 1. Documentos selecionados.

Fonte: Elaborado pelo autor com base no MEC - Portal da Legislaçấo (Governo Federal).

Todo o material foi tratado por meio da análise temática, pois, por meio de sua "liberdade teórica, a análise temática fornece uma ferramenta de pesquisa flexível e útil, que pode potencialmente fornecer um conjunto rico e detalhado, ainda que complexo, de dados" (Braun \& Clarke, 2006, p. 3), permitindo "identificar, analisar e relatar padróes (temas)" (p. 5) a partir desses dados qualitativos mobilizados e interpretados pelo pesquisador. Assim, o tema recortado como unidade de análise, isto é, o profissional de apoio à inclusão escolar, foi mapeado nesses documentos legais e governamentais a partir de suas ocorrências semânticas, a saber: "monitor ou cuidador"; "outros profissionais"; "profissional de apoio"; "acompanhante especializado"; e "profissional de apoio escolar". Os resultados desse trabalho são apresentados no item subsequente, em uma narrativa descritivo-analítica e interpretativa sobre esses termos, seus sentidos e significados no âmbito das alteraçóes documentais e orientaçóes oficiais que circunscrevem a problemática anunciada, em constante diálogo com outras pesquisas correlatas.

\section{Resultados E Discussóes}

A PNEEPEI, publicada em 2008, mas herdeira de discussóes mundiais articuladas desde a década de 1990, em prol do movimento da escola para todos (Bezerra, 2012), forjou o encaminhamento dos estudantes PAEE para as escolas e classes comuns, em especial aqueles com deficiência e transtorno do espectro autista (TEA). Essa situação trouxe necessidade de reorganizar o espaço escolar, que precisava incorporar esse público. Como o foco da PNEEPEI foi o AEE extraclasse em SRM (Mendes, 2017, 2019), abriu-se uma lacuna em relação ao apoio a ser dado ao PAEE na classe comum, o que significaria, também, garantir algum respaldo aos professores para o desenvolvimento de uma prática pedagógica inclusiva. Como analisa Martins (2011),

As normativas mais recentes voltadas à Educação Especial demandam uma forte imposição de que o AEE nas redes de ensino aconteça nas salas de recursos multifuncionais. Tal ênfase enfraquece o trabalho da Educação Especial na classe regular, o qual perdeu a possibilidade de apoio pedagógico especializado e passou a assumir o formato de monitoria e cuidado. (p. 146).

Nesse sentido, recorrer a um profissional de apoio à inclusão escolar pareceu a alternativa mais viável, econômica e legitimada em tempos de Educação Inclusiva. Conforme Martins (2011): "Apesar de na documentação representativa da política nacional o profissional 
de apoio não ser enfatizado, muitas redes municipais e estaduais de educação lançam mão de sua presença como estratégia de realização da política de Educação Especial na perspectiva inclusiva” (p. 35). Entendo que, de início, acreditou-se que a contrataçáo desses profissionais deixaria os professores de classe comum mais predispostos a promover a inclusão escolar, conforme reivindicado pela PNEEPEI, uma vez que, além do suposto respaldo do AEE no contraturno, teriam um "auxiliar" para as demandas mais "físicas" e "braçais" desse processo, no turno das aulas regulares.

Por isso, tal política, embora mencione apenas de forma lacônica sobre esses profissionais, acabou por induzir sua disseminação nas redes públicas de ensino, que buscaram se adequar às novas exigências do cotidiano escolar, mediante ingresso crescente de alunos PAEE. No entanto, uma problemática aí se configurava, na medida em que, para Serra (2017): "Os apoios surgem de forma muitas vezes improvisada, criando mal-estar nas escolas. Neste cenário surge o mediador" (p. 28). Ainda segundo mencionam Nunes, Araújo, Schirmer e Walter (2013):

No Brasil, a necessidade e a urgência em prover atendimento educacional qualificado ao aluno com deficiência no interior da sala regular, como é preconizado nos cânones da educação inclusiva, fizeram emergir esse agente educacional. A partir de 2000, passou a ser frequente nas escolas particulares e, posteriormente, nas escolas públicas a presença do mediador, cujo trabalho se destina a acompanhar crianças que necessitavam de auxílio na sala de aula, em geral sob orientaçáo de profissionais especializados. (p. 67).

Diante dessa realidade, a publicação da Resolução no 4, de 2 de outubro de 2009, pela qual foram instituídas as Diretrizes Operacionais para o Atendimento Educacional Especializado na Educação Básica, modalidade Educação Especial, validou, pela via legal, o que fora indicado apenas como diretriz no texto da PNEEPEI. Essa Resolução tornou-se, portanto, um dos documentos que, sem maiores especificaçóes, legitimou a existência de "outros profissionais" - os não docentes e não pertencentes ao campo da educação formal - como parte do aparato criado para, em tese, garantir a efetividade do modelo de inclusão escolar que era forjado pelas diretrizes nacionais. Muito embora tendo suas funçóes circunscritas à tríade alimentação, higiene e locomoçáo, o profissional de apoio à inclusão escolar estava, porém, articulado à organização do serviço do AEE, isto é, um trabalho de mediação pedagógica especializada, o que, como se depreende, tem impactado nas interpretaçóes sobre a identidade e os limites de atuação desse profissional. De acordo com a Resolução,

Art. 10. O projeto pedagógico da escola de ensino regular deve institucionalizar a oferta do AEE prevendo na sua organização: I - sala de recursos multifuncionais: espaço físico, mobiliário, materiais didáticos, recursos pedagógicos e de acessibilidade e equipamentos específicos; II matrícula no AEE de alunos matriculados no ensino regular da própria escola ou de outra escola; III - cronograma de atendimento aos alunos; IV - plano do AEE: identificação das necessidades educacionais específicas dos alunos, definição dos recursos necessários e das atividades a serem desenvolvidas; $\mathrm{V}$ - professores para o exercício da docência do AEE; VI - outros profissionais da educação: tradutor e intérprete de Língua Brasileira de Sinais, guia-intérprete $e$ outros que atuem no apoio, principalmente às atividades de alimentação, higiene e locomoção [...]. (Resolução n. 4, 2009, p. 2, ênfases adicionadas).

Seguindo essas orientações, as redes públicas de ensino contrataram esses "outros" profissionais de apoio à inclusão escolar, que, conforme o lugar e as condiçôes de empregabili- 
dade, receberam nomes diversos, tais como: cuidador, monitor, mediador, estagiário mediador, auxiliar de ensino, auxiliar de vida escolar, atendente, acompanhante especializado, dentre outros, segundo têm revelado estudos sobre o tema. Entretanto, náo houve uniformidade quanto à formação exigida, às atribuições e carreira desse profissional, que, em diversas localidades, foi e ainda é contratado como estagiário de cursos de licenciatura, especialmente do curso de Pedagogia (Burchert, 2018; Cunha, Glat, Silva, \& Siqueira, 2012; Estef, 2013; Glat \& Pletsch, 2011; Lopes, 2018; Martins, 2011; Serra, 2017; Souza et al., 2012; Stelmachuk \& Mazzotta, 2012; Vicente \& Bezerra, 2017), sujeitos à lei do estágio (Lei no $11.788,2008$ ). Tal circunstância, aliás, torna incômodo o uso da palavra "profissional", pois estaríamos, a rigor, falando de um estudante em formação, o qual, em muitos casos, sem respaldo, é posto para desempenhar o papel de um professor já formado e especialista no assunto.

E, de forma ainda mais preocupante, esse contrato, não raras vezes, sequer é celebrado diretamente com a rede pública de ensino, mas com alguma instituição intermediária, especializada no recrutamento de estagiários, como evidenciado, por exemplo, por Burchert (2018), Lopes (2018) e Vicente e Bezerra (2017). Logo, esse sujeito fica em uma posição ambígua no contexto escolar, pois não sabe se responde ao sistema de ensino onde presta serviço ou à instituição contratante. É um agente educacional, mas, ao mesmo tempo, um terceirizado que vive a precariedade dessa condição. Além disso, como estagiário, só pode permanecer até dois anos nessa função (Lei n ${ }^{\circ} 11.788,2008$ ), o que gera descontinuidade do trabalho desenvolvido e torna a rotatividade desses agentes uma constante, impactando negativamente o processo de inclusão escolar do próprio PAEE. Tais consideraçóes encontram ressonância na análise de Marin e Braun (2013), ao problematizarem o emprego de tais sujeitos para realizarem uma suposta prática de mediação escolar

que ocorre tanto no ensino privado quanto no público e consiste na contratação de um prestador de serviços, o 'mediador', frequentemente um estagiário ou universitário em formação, que permanece em sala de aula para monitorar as açóes e acompanhar o aluno com necessidade especial (Arruda, 2013; Cunha, 2013; Estef, 2013). Não lhe cabe participar dos planejamentos, nem das reunióes escolares; não há envolvimento com o que é decidido, pois ele não está lá como um profissional da escola, mas como um auxiliar que, no melhor dos casos, segue as orientaçóes do professor da turma. (Marin \& Braun, 2013, p. 53).

É válido mencionar que há redes públicas de ensino cujos profissionais de apoio à inclusão escolar são contratados por processo seletivo específico ou já estão sendo efetivados por concurso público. Essa última forma, porém, não é dominante nem é a tendência esperada, sobretudo em tempos de contenção de gastos, como anunciado no país. A pesquisa de Lopes (2018) evidenciou que, no que se refere ao regime de trabalho, por exemplo, "alguns [municípios] trabalham com o contrato temporário, outros já iniciaram processo de concurso, mesmo sem existir uma regulamentação da função” (p. 22). É justamente essa ausência de regulamentação (Lopes, 2018) que tem criado diversos equívocos e levado ao fato de que esse profissional, incorporado ao cotidiano escolar, mesmo sem formação acadêmica para tal, acabe, paradoxalmente, assumindo atribuições didático-pedagógicas que seriam exclusivas de docentes, como diferenciação do ensino, adequaçóes curriculares e/ou preparação de atividades pedagógicas e materiais diferenciados para o PAEE (Burchert, 2018; Cunha et al., 2012; Martins, 2011; Souza et al., 2012; Vicente \& Bezerra; 2017). 
Ora, essa prática - já tornada corriqueira - representa um contrassenso e precarização da própria Educação Especial e da docência (Martins, 2011), ao mesmo tempo que tem gerado e retroalimentado práticas de exclusão na escola que se pretende inclusiva (Bezerra, 2017). Para Bezerra (2012, p. 194): "Nessas condições, a mediação especializada, a cargo do auxiliar, pode ser confundida com mero suporte nas atividades de vida diária ou, então, ocorrer ao sabor do imediatismo e do improviso, haja vista a ausência de formação específica para o desempenho da função". Em vez de se garantir o direito à educação escolar do PAEE e o atendimento de suas necessidades específicas de aprendizagem e desenvolvimento, o que se observa é a mera acomodação da diferença na escola, com o estagiário/profissional de apoio se convertendo em um tutor particular e exclusivo do estudante PAEE, com o papel de a este vigiar e controlar para não perturbar a sala de aula, que continua sendo vista pela óptica da homogeneidade. Desse modo, na acepção de Souza et al. (2012):

O trabalho que os auxiliares realizam, entretanto, é ainda mal compreendido e, nem sempre, constitui-se numa prática realmente inclusiva, pois o professor regente costuma jogar para o monitor toda a responsabilidade sobre o(s) aluno(s) com deficiência, eximindo-se de sua educação e até ignorando-o(s). Nesse contexto, não é raro que existam duas práticas, isto é, a do monitor e a do professor regente. (p. 643-644).

$\mathrm{Na}$ tentativa de dirimir a dubiedade em torno dessa problemática, o MEC, por meio da então Secretaria de Educação Especial (SEESP), chegou a emitir, em 2010, a Nota Técnica no 19 sobre o assunto, um documento que, mesmo sem força de lei, tinha o propósito de apresentar a interpretação oficial sobre as funçóes do profissional de apoio à inclusão escolar. A emissão dessa nota, por si só, revela que o assunto não era questão pacificada em todo o país, a ponto de merecer um pronunciamento do MEC/SEESP. Na nota mencionada, a perspectiva governamental reafirmou que:

Dentre os serviços da educaçáo especial que os sistemas de ensino devem prover estáo os profissionais de apoio, tais como aqueles necessários para promoção da acessibilidade e para atendimento a necessidades especificas dos estudantes no âmbito da acessibilidade às comunicaçōes e da atenção aos cuidados pessoais de alimentaçâo, higiene e locomoçâo. Na organização e oferta desses serviços devem ser considerados os seguintes aspectos:

$[\ldots]$

- Os profissionais de apoio às atividades de locomoção, higiene, alimentaçáo, prestam auxílio individualizado aos estudantes que não realizam essas atividades com independência. Esse apoio ocorre conforme as especificidades apresentadas pelo estudante, relacionadas à sua condição de funcionalidade e não à condição de deficiência.

- A demanda de um profissional de apoio se justifica quando a necessidade específica do estudante público alvo da educação especial não for atendida no contexto geral dos cuidados disponibilizados aos demais estudantes.

- $[\ldots]$

- Não é atribuição do profissional de apoio desenvolver atividades educacionais diferenciadas, ao aluno público alvo da educação especial, e nem responsabilizar-se pelo ensino deste aluno.

[...]. (Nota Técnica no 19, 2010, p. 144-145, ênfases adicionadas).

Embora longa, a transcrição é fundamental para que se perceba o posicionamento oficial, rechaçando a possibilidade de envolvimento do profissional de apoio nas incumbências do ensino dos estudantes PAEE. Náo obstante, a nota técnica, conquanto tenha pretendido 
fazer dessa ressalva uma unanimidade, acabou por, novamente, silenciar quanto à formação e à identidade profissional desses sujeitos, o que manteve as contradiçóes e as confusóes em torno de seu papel e de suas qualificações ao cargo. Posteriormente, por pressão de grupos de familiares e setores da sociedade civil organizada, a aprovação da Lei no 12.764 (2012), a Lei de Proteção à Pessoa com Transtorno do Espectro Autista, introduziu o termo "acompanhante especializado", que, invariavelmente, repercutiu no entendimento que se vinha construindo acerca desse que era, até então, nomeado como profissional de apoio. Como disposto na lei, Art. 3º, parágrafo único:

São direitos da pessoa com transtorno do espectro autista:

$[\ldots]$

Parágrafo único. Em casos de comprovada necessidade, a pessoa com transtorno do espectro autista incluída nas classes comuns de ensino regular, [...], terá direito a acompanhante especializado. (Lei $n^{\circ} 12.764,2012$, ênfases adicionadas).

Ao ter grande repercussão social e veiculação midiática, essa lei popularizou o apelo em torno do acompanhante especializado, entendido como uma vitória dos grupos e familiares envolvidos com a causa do TEA. O termo, contudo, agravou as confusóes já (re)produzidas no espaço escolar. Isso porque famílias e órgãos judiciais passaram a pressionar escolas e sistemas de ensino para o cumprimento imediato do disposto, em um fenômeno da judicialização da educação inclusiva (Serra, 2017). Para problematizar o exposto, não se pode perder de vista que os documentos anteriores adotavam o termo monitor, cuidador ou profissional de apoio, como já citado. Ora, esse acompanhante especializado seria correspondente ao profissional de apoio, segundo já descrito, ou seria um professor com formação em Educação Especial, isto é, um professor especializado nesse segmento? Ou poderia ser um profissional que, mesmo sem nível superior, tivesse capacitação na área? O termo especializado não sugeriria alguma formação mínima e específica a esse acompanhante, diferenciando-o, a princípio, do mero profissional de apoio/monitor descrito em textos anteriores? Se assim fosse, qual seria essa formação que o titularia de "especializado"?

Novamente, para atenuar as ambiguidades suscitadas, o MEC, por meio da Secretaria de Educação Continuada, Alfabetização, Diversidade e Inclusão (SECADI), emitiu, em 2013, outra nota técnica. Quando a analisamos, porém, depreendemos que o acompanhante especializado, na concepção oficial, equivaleria ao mesmo profissional de apoio anteriormente especificado, com o destaque de que também seria encarregado de organizar a acessibilidade do estudante com TEA à comunicação, medida que, aliás, já estava prevista nas diretrizes de 2010 (Nota Técnica no 19, 2010). Assim, a Nota Técnica no 24, de 2013, trouxe orientação aos sistemas de ensino para a implementaçáo da Lei no 12.764 , 2012, afirmando que:

No art. $3^{\circ}$, parágrafo único, a referida lei assegura aos estudantes com transtorno do espectro autista, o direito à acompanhante, desde que comprovada sua necessidade. Esse serviço deve ser compreendido a luz do conceito de adaptaçáo razoável [...].

O serviço do profissional de apoio, como uma medida a ser adotada pelos sistemas de ensino no contexto educacional deve ser disponibilizado sempre que identificada a necessidade individual do estudante, visando à acessibilidade às comunicaçóes e à atenção aos cuidados pessoais de alimentação, higiene e locomoçáo. Dentre os aspectos a serem observados na oferta desse serviço educacional, destaca-se que esse apoio: $\square$ Destina-se aos estudantes que não realizam as atividades de alimentação, higiene, comunicação ou locomoção com autonomia e independência, 
possibilitando seu desenvolvimento pessoal e social; - Justifica-se quando a necessidade específica do estudante não for atendida no contexto geral dos cuidados disponibilizados aos demais estudantes; - Não é substitutivo à escolarização ou ao atendimento educacional especializado, mas articula-se às atividades da aula comum, da sala de recursos multifuncionais e demais atividades escolares [...]. (Nota Técnica no 24, 2013, n.p., grifos meus).

A Lei de Proteção à Pessoa com TEA, por sua vez, foi regulamentada em 2014, por decreto que manteve a nomenclatura "acompanhante especializado", mas discriminando, dessa vez, suas funçóes no espaço escolar. Estas foram redigidas ao encontro do que fora apresentado na Nota Técnica de 2013 (Nota Técnica no 24, 2013), com o acréscimo de mais uma atribuição ao profissional: apoio à interação social (Decreto $\left.{ }^{\circ} 8.368,2014\right)$. Evidentemente, a preocupação desses últimos documentos em explicitar as atividades de interaçáo social e comunicação como parte dos apoios a serem organizados na instituiçáo escolar revelam o destaque que os sujeitos com TEA vão ganhando no contexto decorrente da PNEEPEI, haja vista a organização das entidades representativas desse segmento e de suas famílias, a ponto de se promover uma Política Nacional de Proteção dos Direitos da Pessoa com TEA (Decreto ${ }^{\circ}$ 8.368, 2014; Lei ${ }^{\circ}$ $12.764,2012)$. O excerto a seguir ratifica o exposto, prevendo que:

Caso seja comprovada a necessidade de apoio às atividades de comunicação, interaçáo social, locomoção, alimentação e cuidados pessoais, a instituição de ensino em que a pessoa com transtorno do espectro autista ou com outra deficiência estiver matriculada disponibilizará acompanhante especializado no contexto escolar [...]. (Decreto $n^{\circ} 8.368,2014$, art. $4^{\circ}, \$ 2$, ênfases adicionadas).

Pois bem, chegado a esse ponto, é preciso atentar para algumas lacunas que decorrem a partir da legislação citada. Já argumentei que, quando menciona "acompanhante especializado", em 2012, a lei não esclarece quem seria esse profissional, não especifica suas atribuiçóes - tanto que o MEC precisou divulgar Nota Técnica a respeito - e condiciona a sua presença no espaço escolar à comprovada necessidade do estudante com TEA (Lei n ${ }^{\circ} 12.764,2012$; Nota Técnica no 24, 2013). Há de perguntar-se, no entanto, quem comprovaria essa necessidade do estudante? A família? A escola? Outra vez não há resposta em nenhuma legislação nacional, abrindo brecha para que estados e municípios criem suas regulamentaçóes e, o que é preocupante, valide-se o modelo médico da deficiência e desenvolvimento humano. Nessas condiçóes, a responsabilidade de indicar a necessidade ou não de acompanhante vai sendo atribuída, inclusive pelas redes públicas de ensino, aos médicos, psicólogos e a outros profissionais da saúde (Bezerra, 2017), muitas vezes pressionados ou induzidos por familiares quanto à elaboraçáo de laudos ou diagnósticos clínicos para que estes possam reclamar a presença do acompanhante especializado para seus filhos/parentes.

Ainda na direção do exposto, lembro que, ao explicitar as funçóes desse acompanhante, em 2014, fica patente que, em tese, este seria mesmo apenas um profissional de apoio, nos moldes como vinha sendo previsto desde 2008, em que pesem as oscilaçóes de nomenclatura. Por conseguinte, seu papel não invadiria, a rigor, as competências do docente (comum e/ou especializado), tendo-se observado somente que, de uma tríade, passou-se a uma lista com cinco quesitos a serem observados pelo acompanhante especializado no exercício de suas atividades (Decreto $\left.\mathrm{n}^{\circ} 8.368,2014\right)$. As interpretaçóes dúbias, porém, não se esgotaram, pois, embora promulgado para regulamentar a Lei ${ }^{\circ} 12.764$, de 2012, o citado Decreto novamente 
não normatizou (ou deixou propositalmente em aberto) os critérios possíveis de formação desse profissional. Conseguintemente, permanece a indagação: como esse sujeito poderia apoiar os processos de interação social, comunicação, alimentação, locomoçãa e cuidados pessoais a serem desenvolvidos junto aos estudantes com TEA ou deficiência sem alguma formação pedagógica especializada?

Ademais, esses processos são, também, educacionais e estão articulados ao desenvolvimento integral do ser humano. Sobretudo na escola, não poderiam ser vistos como espontâneos e nem tradados de forma assistemática. O que significa, afinal, especializado, nesse caso? Será que a palavra estaria sendo empregada apenas na acepção de um apoio "exclusivo" para os estudantes PAEE, em flagrante oposição aos princípios de uma escola inclusiva e colaborativa? Ao que parece, tais indefinições são politicamente estratégicas e convenientes ao Governo Federal, permitindo que, em um país de nossa amplitude continental, as redes municipais e estaduais se organizassem conforme suas possibilidades, recursos e intenções, porquanto, de fato, são nessas instâncias que a PNEEPEI se realiza e é traduzida segundo compreensóes diversas.

Destarte, em diferentes locais, muitos interpretaram o termo acompanhante especializado como se fosse um professor especializado, a despeito das indicaçóes governamentais irem de encontro a essa leitura, consoante a análise exposta. Criou-se, entáo, uma ideia equivocada de que todo aluno com TEA e com deficiência automaticamente teria direito a um professor de apoio na classe comum, o que, como vimos, não é o que diz a legislação. Outros lugares entenderam que o apoio poderia ser um profissional não docente, com ou sem capacitações específicas na área da Educação Especial. Dito de outro modo, a palavra "especializado" foi e continua sendo lida em diferentes sentidos e de acordo com as conveniências ou recursos financeiros disponíveis.

Por fim, ainda no bojo dessas disputas semânticas, a Lei Brasileira de Inclusão (LBI) (Lei $\left.\mathrm{n}^{\circ} 13.146,2015\right)$ regulamentou a expressão profissional de apoio escolar, que também vinha sendo usada desde o início de vigência da PNEEPEI. Desse modo, a LBI quis afastar confusões e desvios de função, ao explicitar que o trabalho desse profissional não poderia invadir o campo de atuação de profissóes já demarcadas, como o dos professores e profissionais da saúde. Isso significou restringir a atuação do profissional de apoio unicamente aos afazeres de um cuidador, mais uma vez recuperando as proposiçóes iniciais da PNEEPEI conforme já relatado. Serra (2017, p. 31) analisa que "A Lei Brasileira de Inclusão define parcialmente as regras sobre a contratação do mediador. Fica clara a responsabilidade da escola, mas continuam indefinidas a formação do mediador, piso salarial e regras de contratação [...]”. Na definição da LBI, lê-se, textualmente, o seguinte:

profissional de apoio escolar: pessoa que exerce atividades de alimentação, higiene e locomoção do estudante com deficiência e atua em todas as atividades escolares nas quais se fizer necessária, em todos os níveis e modalidades de ensino, em instituições públicas e privadas, excluídas as técnicas ou os procedimentos identificados com profissöes legalmente estabelecidas. (Lei ${ }^{\circ} 13.146,2015$, art. $3^{\circ}$, XIII, ênfases adicionadas).

Diante do exposto, observo que, enquanto se discute a questão do profissional de apoio escolar/acompanhante especializado em si mesma, tomada como bandeira de luta por grupos familiares, entidades e políticos, de modo que ter ou não ter esse agente na escola assu- 
me a centralidade das discussões sobre os direitos de escolarização do PAEE em classe comum, com poucos questionamentos sobre a identidade e constituição do profissional em evidência, tem-se obliterado uma questão de fundo. Em outras palavras, pouco destaque se dá à luta por uma compreensão ampliada de AEE, que venha a englobar "um conjunto de apoios diversificados necessários para responder às diferentes demandas da escolarização de alunos PAEE nas escolas comuns" (Mendes, 2017, p. 81) e se promova, como cerne da política pública inclusiva, o ensino colaborativo, o qual

consiste em uma parceria entre os professores de Educação Regular e os professores de Educação Especial, na qual um educador comum e um educador especial dividem a responsabilidade de planejar, instruir e avaliar os procedimentos de ensino a um grupo heterogêneo de estudantes. (Ferreira, Mendes, Almeida, \& Del Prette, 2007, p. 1).

Isso não quer dizer que a presença de profissionais de apoio à inclusão escolar não seja, também, uma necessidade para as redes públicas de ensino. O que desejo ressaltar é que não se pode crer que estes, ainda sem carreira definida e sem regulamentaçóes precisas de sua atuação, a qual se torna objeto de interpretaçóes múltiplas, sejam postos como o principal respaldo para a permanência de estudantes PAEE nas classes comuns. Meu posicionamento pode ser justificado quando se nota que esses profissionais, quase sempre com formação de nível médio (com ou sem habilitação específica para o magistério) ou ainda estudantes universitários, com ou sem alguma capacitaçáo na área, representam uma precarização da atençáo educacional ao público que mais necessita de suporte, não só em demandas de cuidados pessoais e de vida diária, mas, a fortiori, de atenção pedagógica. Por isso, de acordo com Bezerra (2012),

a contratação de estagiários ou auxiliares, justamente para atender alunos que requerem apoios intensos e sistematizados, em virtude de síndromes, deficiências ou outras formas de desenvolvimento diferenciado, longe de representar a 'solução' dos desafios aludidos, demonstra a materializaçáo do 'atendimento universal precário' (Kassar; Arruda; Benatti, 2007, p. 29) ofertado aos alunos com (e sem) deficiência na escola para todos. (p. 193-194).

Ademais, é diante dessa indefinição quanto à figura do profissional de apoio/acompanhante especializado, cujo nome acaba confundindo os leigos, como se se tratasse de um professor especializado, que governos têm priorizado a contratação de agentes educacionais com nível médio ou em formação, difundindo a ideia de que, com a presença destes, todas as demandas da classe comum estariam satisfeitas do ponto de vista legal e pedagógico, em vez de investir no ensino colaborativo propriamente dito. E, mais ainda, corre-se o risco de um desinvestimento no ensino colaborativo onde este vinha se constituindo, haja vista que, na ausência de especificação legal, redes públicas de ensino aderem à alternativa mais barata, qual seja, o profissional de apoio não docente. Como alerta Mendes (2017),

A ênfase atual na educação está na busca pela excelência nas escolas, gastando o mínimo possível, e tanto o aumento nas exigências e padróes de desempenho quanto as despesas, consideradas adicionais, para atender às necessidades do público-alvo da Educação Especial, complicam esse cenário porque impactam o financiamento da educação e questionam a funçáo da escola pretendida pelos reformadores. (p. 82). 
Nessas condições, os governos, na melhor das hipóteses, fornecem a esses agentes algum curso na área e justificam que o requisito "especializado" está sendo cumprido, dispensando professores especializados do trabalho da classe comum, os quais ficam restritos às funçóes do AEE em SRM, um serviço que não tem apresentado resultados satisfatórios para o avanço do processo de inclusão escolar (Mendes, 2017, 2019). Afinal, o AEE em SRM possibilita, quando muito, interaçóes pontuais entre professores de classe comum e especializados, distantes no tempo e no espaço, ao contrário de uma prática colaborativa em que atuam “juntos na mesma classe, quando há a presença de um ou mais alunos que demandam uma atenção diferenciada" (Marin \& Maretti, 2014, p. 3). Assim, sob o argumento de economia e otimização de verbas públicas, insiste-se em um modelo de inclusão escolar que pouco prioriza a sala de aula comum e que, por consequência, negligencia o PAEE, tornados "novos excluidos de dentro do nosso sistema escolar" (Bezerra, 2017, p. 494). Daí a compreensão, quanto ao caso analisado, de que

este implica em um cargo novo nas redes de ensino. Constitui um processo de intensificação do trabalho docente realizado no âmbito de um cargo precarizado/desvalorizado com relaçáo ao trabalho do professor regente. Explicita, ainda, o modelo de inclusão escolar difundido pelos documentos oficiais ao assumir uma característica de pouca, ou nenhuma ênfase, nas questóes pedagógicas. Mantém a prática orientada por diagnósticos reforçada pela realização de cursos que identificam o aluno pelas características do diagnóstico de deficiência e não como sujeito de direitos. (Martins, 2011, p. 150).

Nota-se, então, um descompasso entre o objetivo pretendido pela PNEEPEI, qual seja, o de "assegurar a inclusão escolar de alunos com deficiência, transtornos globais do desenvolvimento e altas habilidades/superdotação, orientando os sistemas de ensino para garantir: acesso ao ensino regular, com participação, aprendizagem" (PNEEPEI, 2008, p. 14), e os efeitos decorrentes de sua operacionalização nos últimos anos. Essa tendência se agrava quando a política vigente é a de economia, congelamento e corte de investimentos nos sistemas públicos de ensino, circunstância que atinge duplamente os estudantes PAEE. Estes, afinal, tanto quanto seus demais colegas, já convivem "numa escola específica, a brasileira, que apresenta um dos piores desempenhos do planeta, segundo avaliaçóes padronizadas internacionais de larga escala" (Mendes, 2017, p. 76).

Por isso, o ensino colaborativo não pode ser encarado como "luxo" ou um termo acessório de uma política educacional que se pretenda inclusiva, mas como um meio imprescindível de democratizar as oportunidades de acesso, com condiçóes tais de se alcançar permanência com sucesso, à escola comum para todos os estudantes, com e sem necessidades específicas de aprendizagem. Nesse sentido, é preciso ter em consideração a perspectiva de que "trabalho dos profissionais de apoio deve ser analisada sob a ótica da proposta de desmonte da escola escamoteada sobre o discurso de 'universalização do ensino' e 'escola para todos” (Martins, 2011, p. 106). E, certamente, a atribuição dos papéis de monitoria e cuidado a eles, sem a contrapartida da mediação de um docente especializado na classe comum, cerceia a ideia de planejamento colaborativo e de se pensar nas formas de apropriaçáo do conhecimento escolar pelo PAEE, haja vista que essas não são funções do profissional de apoio escolar. Afinal, o aspecto "especializado" de seu trabalho diz respeito, tão somente, ao saber-fazer instrumental de um cuidador, se nos pautarmos pelo que se depreende dos documentos e das orientaçóes analisados. 


\section{CONSIDERAÇÓES FINAIS}

Com este artigo, problematizei um dos efeitos colaterais da atual PNEEPEI, qual seja: o profissional de apoio à inclusão escolar/acompanhante especializado. Essa figura tem funçóes específicas, se considerarmos a legislação e as diretrizes oficiais, que não compreendem questóes curriculares e didático-pedagógicas. No entanto, como revelado pelas pesquisas, tal profissional acaba sendo posto na função equivalente a de um professor especializado, o que pode ser lido como precarização das condiçóes de trabalho docente, à medida que se desqualifica a formação especializada e o papel do professor da Educação Especial, em nome de alternativas consideradas mais baratas do ponto de vista econômico para as redes públicas de ensino. Essa situação revela que a PNEEPEI deu ênfase ao AEE extraclasse, o que abriu caminho para que soluçóes paliativas fossem buscadas para viabilizar o ensino dos alunos PAEE em classe comum.

Por conseguinte, em vez de pensar-se em uma gama de serviços e suportes para a constituição de uma escola inclusiva, tem-se centrado o foco apenas nesses alunos, como se o "problema" fosse o indivíduo, a quem se deve identificar para melhor exercer vigilância e garantir seu isolamento, mesmo permanecendo no interior da sala de aula, com toda a turma. Como lembram Cunha et al. (2012, p. 7), "Diante dessa realidade o estagiário acaba por fazer um papel de 'cuidador' ou até mesmo 'babá', vigiando e contornando situaçóes para que a criança não atrapalhe ou prejudique o decorrer da aula”. Nessas condições, o apoio intraclasse ao processo de inclusão escolar fica comprometido e se inviabiliza a emergência do ensino colaborativo, porquanto se difunde a ideia de que os estudantes PAEE, mediante a presença de profissionais de apoio à inclusão escolar, representados por estagiários em formação ou até mesmo por agentes com formação de nível médio, eventualmente apenas com capacitaçóes pontuais, estão devidamente assistidos, sem demandar mais investimentos para sua aprendizagem e desenvolvimento.

Assim, seguindo à risca as normativas oficiais, cujo foco é o cuidado e a monitoria do alunado PAEE, justifica-se a não exigência de uma formação pedagógica, "o que favorece a minimização por parte do profissional de apoio de funçóes pedagógicas, mesmo atuando num espaço destinado por excelência ao ensino e aprendizagem” (Martins, 2011, p. 35). Contribui para a manutenção dessa realidade as próprias ambiguidades da legislação brasileira e das recomendações decorrentes da PNEEPEI sobre o tema, como apresentado. Não se trata, porém, de negar a relevância do profissional de apoio, cujo trabalho empírico precisa continuar a ser pesquisado em novos estudos, mas de se esclarecer que este não pode ser entendido pelas redes públicas de ensino como substituto mais "econômico" dos professores especializados. Ambos são suportes imprescindíveis à classe comum inclusiva, mas com suas respectivas funçóes, as quais se complementam em processos de colaboração entre toda a comunidade escolar. Nesses termos, é mister "que a criação de cargos e recursos não fragmente a proposta de atendimento ao aluno da educação especial, mas contrariamente, concretize uma possibilidade e atuação multiprofissional em rede" (Burchert, 2018, p. 73).

É fundamental, portanto, que a legislação posterior seja explícita quanto ao significado de termos como "acompanhante especializado", normatize as funçóes, piso salarial e defina formações mínimas a serem exigidas desses profissionais de apoio à inclusão escolar na direção do exposto pela LBI. Além disso, espera-se que novas diretrizes nacionais, sobretudo 
com a possível reformulação da PNEEPEI, possibilitem a emergência de alternativas mais condizentes com as necessidades específicas desse público, trazendo-lhes justiça curricular, isto é, apropriação dos conhecimentos escolares e aprendizagem mediante os suportes que se fizerem necessários, para além da mero cuidado e de sua presença tutelada nas classes comuns. Para tanto, o ensino colaborativo deve ser tomado como a principal referência de (re)organização da escola inclusiva. E, se a preocupação é com a economia de recursos, é válido lembrar que, mediante atuação dos professores especializados nas turmas em que existam alunos PAEE, os próprios profissionais de apoio, com orientação dos demais docentes, podem se tornar itinerantes pela instituição escolar, sem se fixarem em uma sala, o que certamente diminuirá o ônus da contratação desses profissionais e o impacto de sua (oni)presença sobre os estudantes que deles necessitam. Eis as possibilidades que se abrem para (re)pensarmos os fazeres e saberes da inclusão escolar.

\section{REFERÊNCIAS}

Bezerra, G. F. (2012). Enquanto não brotam as flores vivas: crítica à pedagogia da inclusão. Dissertação de Mestrado, Universidade Estadual de Mato Grosso do Sul, Paranaíba, Mato Grosso do Sul, Brasil.

Bezerra, G. F. (2017). A inclusão escolar de alunos com deficiência: uma leitura baseada em Pierre Bourdieu. Revista Brasileira de Educação, 22(69), 475-497. DOI: https://doi.org/10.1590/s141324782017226924

Braun, V., \& Clarke, V. (2006). Using thematic analysis in psychology. Qualitative Research in Psychology, 3(2), 77-101. Recuperado em 29 de novembro de 2019 de https:/www.tandfonline.com/doi/ abs/10.1191/1478088706qp063oa

Burchert, A. (2018). O profissional de apoio no processo de inclusão de alunos público-alvo da Educação Especial no ensino público fundamental. Dissertação de Mestrado, Universidade La Salle, Canoas, Rio Grande do Sul, Brasil. Recuperado em 27 de novembro de 2019 de http://dspace.unilasalle.edu.br/bitstream/11690/1131/1/aburchert.pdf

Cunha, N. M., Glat, R., Silva, S. E., \& Siqueira, C. F. O. (2012). O perfil e a formação do estagiário mediador para suporte da educação inclusiva. Artigo apresentado no $5^{\circ}$ Congresso Brasileiro de Educação Especial, São Carlos, São Paulo, Brasil, Recuperado em 24 de junho de 2016 de http:// www.eduinclusivapesq-uerj.pro.br/images/pdf/Nathalia.Ufscar.2012.2.pdf

Decreto $n^{\circ}$ 8.368, de 2 de dezembro de 2014. Regulamenta a Lei no 12.764, de 27 de dezembro de 2012, que institui a Política Nacional de Proteção dos Direitos da Pessoa com Transtorno do Espectro Autista. Recuperado em 27 de novembro de 2019 de http://www.planalto.gov.br/ccivil_03/_ Ato2011-2014/2014/Decreto/D8368.htm

Estef, S. (2013). Ensino colaborativo sob o olhar de uma estagiária mediadora no cotidiano escolar. Graduação em Pedagogia, Faculdade de Educação, Universidade do Estado do Rio de Janeiro, Rio de Janeiro, Brasil. Recuperado em 27 de novembro de 2019 de http://www.eduinclusivapesq-uerj. pro.br/images/pdf/SuzanliEstef_Monografia_2013.pdf

Ferreira, B. C., Mendes, E. G., Almeida, M. A., \& Del Prette, Z. A. P. (2007). Parceria colaborativa: descrição de uma experiência entre o ensino regular e especial. Revista Educação Especial, 29, 1-7.

Gil, A. C. (1991). Como elaborar projetos de pesquisa. São Paulo: Atlas. 
Glat, R., \& Pletsch, M. D. (2011). Inclusão escolar de alunos com necessidades educacionais especiais. Rio de Janeiro: EdUERJ.

Lei no 11.788, de 25 de setembro de 2008. Dispóe sobre o estágio de estudantes. Recuperado em 27 de novembro de 2019 de http://www.planalto.gov.br/ccivil_03/_ato2007-2010/2008/lei/l11788.htm

Lei no 12.764, de 27 de dezembro de 2012. Institui a Política Nacional de Proteção dos Direitos da Pessoa com Transtorno do Espectro Autista. Recuperado em 27 de novembro de 2019 de http://www. planalto.gov.br/ccivil_03/_Ato2011-2014/2012/Lei/L12764.htm

Lei no 13.146, de 6 de julho de 2015. Institui a Lei Brasileira de Inclusão da Pessoa com Deficiência (Estatuto da Pessoa com Deficiência). Recuperado em 27 de novembro de 2019 de http://www. planalto.gov.br/ccivil_03/_ato2015-2018/2015/lei/l13146.htm

Lopes, M. M. (2018). Perfil e atuação dos profissionais de apoio à inclusão escolar. Dissertação de Mestrado, Departamento de Psicologia, Universidade Federal de São Carlos, São Carlos, São Paulo, Brasil. Recuperado em 26 de novembro de 2019 de https://repositorio.ufscar.br/bitstream/handle/ ufscar/9899/LOPES_Mariana_2018.pdf?sequence=4

Marin, M., \& Braun, P. (2013). Ensino colaborativo como prática de inclusão escolar. In R. Glat, \& M. Pletsch (Eds.), Estratégias educacionais diferenciadas para alunos com necessidades especiais (pp. 49-64). Rio de Janeiro: EdUERJ.

Marin, M., \& Maretti, M. (2014). Ensino colaborativo: estratégia de ensino para a inclusão escolar. Artigo apresentado no $1^{\circ}$ Seminário Internacional de Inclusão Escolar: práticas em diálogo, Rio de Janeiro, Rio de Janeiro, Brasil. Recuperado em 29 de novembro de 2019 de http://www.cap.uerj. $\mathrm{br} /$ site/images/stories/noticias/4-marin_e_maretti.pdf

Martins, S. M. (2011). O Profissional de Apoio na Rede Regular de Ensino: a precarização do trabalho com os alunos da Educação Especial. Dissertação de Mestrado, Centro de Ciências da Educação, Universidade Federal de Santa Catarina, Florianópolis, Santa Catarina, Brasil. Recuperado em 27 de novembro de 2019 de https://repositorio.ufsc.br/bitstream/ handle/123456789/95218/297802.pdf?sequence=1\&isAllowed $=y$

Mendes, E. G. (2017). Sobre alunos “incluídos” ou "da inclusão": reflexôes sobre o conceito de inclusão escolar. In S. L. Victor, A. B. Vieira, \& I. M. Oliveira (Eds.), Educação especial inclusiva: conceituaçôes, medicalização e políticas (pp. 60-83). Campos dos Goytacazes: Brasil Multicultural.

Mendes, E. G. (2019). A política de educação inclusiva e o futuro das instituiçóes especializadas no Brasil. Arquivos Analiticos de Políticas Educativas, 27(22), 1-23. Recuperado em 17 de setembro de 2019 de https://epaa.asu.edu/ojs/article/view/3167/2217

Nota Técnica no 19 (2010). Profissionais de apoio para alunos com deficiência e transtornos globais do desenvolvimento matriculados nas escolas comuns da rede pública de ensino. In Ministério da Educação (2016). A consolidação da inclusão escolar no Brasil (2003-2016) (pp. 205-207). Brasília: MEC. Recuperado em 27 de novembro de 2019 de http://feapaesp.org.br/material_download/571_

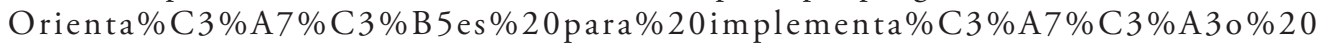
da\%20 Educa $\%$ C 3\%A7\%C3\%A3o\%20Especial $\% 20$ na $\% 20$ Perspectiva $\% 20$ da $\% 20$ Educa\%C3\%A7\%C3\%A3o\%20Inclusiva.pdf

Nota Técnica no 24 (2013). Orientação aos Sistemas de Ensino para a implementação da Lei $n^{o}$ 12.764/2012. In Ministério da Educação (2016). A consolidação da inclusão escolar no Brasil (2003-2016) (pp. 109-114). Brasília: MEC. Recuperado em 27 de novembro de 2019 de http://feapaesp.org.br/material_download/571_Orienta\%C3\%A7\%C3\%B5es\%20para\%20 
implementa\%C3\%A7\%C3\%A3o\%20da\%20Educa\%C3\%A7\%C3\%A3o\%20Especial\%20 na\%20Perspectiva\%20da\%20Educa\%C3\%A7\%C3\%A3o\%20Inclusiva.pdf

Nunes, L. R. O. de P., Araújo, C. A. G. de, Schirmer, C. R., \& Walter, C. C. de F. (2013). A prática pedagógica de mediadoras de alunos com deficiência física e dificuldades na comunicação em escolas do Rio de Janeiro. In R. Glat, \& M. Pletsch (Eds.), Estratégias educacionais diferenciadas para alunos com necessidades especiais (pp. 65-90). Rio de Janeiro: EdUERJ.

Política Nacional de Educação Especial na Perspectiva da Educação Inclusiva (2008). Documento elaborado pelo Grupo de Trabalho nomeado pela Portaria Ministerial no 555, de 5 de junho de 2007, prorrogada pela Portaria no 948, de 09 de outubro de 2007, entregue ao Ministro da Educaçáo em 07 de janeiro de 2008. Brasília: MEC. Recuperado em 27 de novembro de 2019 de http://portal. mec.gov.br/arquivos/pdf/politicaeducespecial.pdf

Resolução no 4, de $1^{\circ}$ de outubro de 2009. Institui Diretrizes Operacionais para o Atendimento Educacional Especializado na Educação Básica, modalidade Educação Especial. Recuperado em 27 de novembro de 2019 de http://portal.mec.gov.br/dmdocuments/rceb004_09.pdf

Serra, D. (2017). A educação inclusiva em tempos de judicialização do estado: o cotidiano das escolas com a lei Brasileira de inclusão - no 13.146/2015. Polêm!ca, 17(1), 27-35. Recuperado em 27 de novembro de 2019 de https://www.e-publicacoes.uerj.br/index.php/polemica/article/view/28294

Souza, A. C. de, Bezerra, G. F., Bezerra, M. F., Costa, P. do N., \& Nozu, W. C. S. (2012). A inclusão escolar no município de Paranaíba (MS): reflexóes sobre a atuação profissional do monitor de alunos com deficiência. Revista Pedagógica - Unochapecó, 2(29), 635-664. Recuperado em 10 de setembro de 2015 de http://bell.unochapeco.edu.br/revistas/index.php/pedagogica/article/view/1467

Stelmachuk, A. C. da L., \& Mazzotta, M. J. da S. (2012). Atuaçáo de profissionais da educaçáo na inclusão escolar do aluno com deficiência intelectual. Revista Educação Especial, 25(43), 185-202. Recuperado em 24 de junho de 2016 de https://www.redalyc.org/pdf/3131/313127405002.pdf

Vicente, B. T., \& Bezerra, G. F. (2017). Estagiários e professores regentes como agentes do processo de inclusão escolar: problematizando suas (inter)açôes. Revista Linhas, 18(38), 214-244. Recuperado em 17 de setembro de 2019 de http://www.revistas.udesc.br/index.php/linhas/article/ view/1984723818382017214/pdf

Recebido em: 30/11/2019

Reformulado em: 04/05/2020

Aceito em: 06/07/2020 